\title{
A framework for rethinking the pedagogy of studio-based design classrooms
}

\author{
David Sinfield \\ School of Art and Design, Auckland University of Technology, New Zealand. \\ David.sinfield@aut.ac.nz
}

\author{
Thomas Cochrane \\ Centre for the Study of Higher Education, the University of Melbourne, Australia. \\ Cochrane.t@unimelb.edu.au
}

This paper explores the application of a design-based research (DBR) methodology to inform the re-design of pedagogical strategies for studio-based classrooms within undergraduate higher education programmes. The goal is to establish a transferable model that is student-centred around authentic educational and professional learning environment as described as Dewey for the digital age. The paper outlines the initial analysis and exploration stage of a DBR methodology that leads to the development of a proposed ecology of resources designed to stimulate rhizomatic pedagogical environments intended to support collaborative student teams rather than the traditional classroom structure. The main aim of this conceptual framework is to enable the design of alternative models to the studio or classroom environment that can enhance and improve traditional teacher-centric environments through focusing upon what the student does and their graduate profiles. These ontological pedagogies will guide the student through the educational process but also provide them with the necessary capabilities to enter into the professional design based working environment once they have graduated. The application of the framework is illustrated by a proposed design curriculum restructure mapped to the framework, and the implementation of a summer school student project.

Keywords: Atelier, social learning environments, rhizomatic learning, ontological pedagogies, heutagogy, design-based research, collaborative curriculum design.

\section{Introduction}

The graphic design sector contributes over $\$ 1.431$ billion to the New Zealand (NZ) economy (DesignCo \& PwC, 2017), and is the largest design sector by a number of designers in NZ

(https://designersinstitute.nz/community/tab/membership/). While the largest design sector, graphic design has also undertaken substantial technological transformation over the past 10-15 years from being largely oriented to design for physical print platforms, to design for digital and interactive media platforms. For example, digital online newspapers and social media (i.e. through smartphone use (Edwards, 2017)) have increasingly replaced traditional print media formats.

Parallel to the decline in print media has been the growth of digital media industries such as online marketing, ecommerce, e-books, online learning, data visualisation, interactive storytelling, moving image, motion graphics for web, cinema and film. For example, the value of the global film industry, which includes motion graphics, is predicted to grow from US \$38 billion in 2016 to nearly US $\$ 50$ billion in 2020 (Watson, 2020). New digital technologies are also creating new business and design opportunities. Design for virtual and augmented reality, which has emerged recently as a key technology platform, is predicted to become a $\$ 150$ billion-dollar global industry within the next five years (Brownlee, 2016). Aligned with the transition of design from print to digital media has been the increasing demand for specialised, highly creative, graphic design graduates who have strong design capabilities across digital technologies. This includes technologies for moving image, motion graphics, interactive digital media, augmented and virtual reality (AR/VR), typography-in-motion, and digital illustration.

The rapid change in the graphic design profession has led to the need for redesigning the graphic design curriculum responding to these technological developments, and the growing demand for graduates with strong graphic design capabilities, which are underpinned by specialist capabilities in utilising multi-platform digital moving image, and interactive technologies. This also aligns with and builds on, the development and rollout out of government policy and education strategies from the Ministry of Education, the Digital Technologies Strategy for the primary and 
secondary school sectors (Ministry of Education, 2017). It is important to note that designing and developing digital outcomes, and design and visual communication are two of four key threads in this strategy. As the strategy rolls out, it is anticipated that there will be an increase in the digital literacy and design capabilities of secondary school graduates, and growth in interest for study in digitally oriented, tertiary-level programmes in future years. In this paper we explore a design-based research curriculum redesign framework that can be transferable to other designbased learning environments, for example, architecture, product design, and digital design.

\section{Ontological Pedagogies}

The underlying pedagogies that inform our curriculum redesign can be broadly described as ontological pedagogies - pedagogies that are concerned with students becoming change agents within the profession of graphic design rather than passive recipients of the delivery of a set curriculum of content. This involves the design of creative but safe spaces for students to explore the boundaries and intersection of graphic design and new technologies. Danvers (2003) describes such learning spaces:

Creativity thrives in an atmosphere that is supportive, dynamic, and receptive to new ideas and activities. The learning environment has to encourage interactions between learners in which: action and reflection are carefully counter-balanced; open-ended periods of play and 'blue-sky' thinking alternate with goal-oriented problem-solving; stimulating inputs and staff interventions are interwoven with periods in which learners develop ideas and constructs at their own pace; critical thinking and robust debate co-exist with a supportive 'space' in which risk-taking, imaginative exploration and productive failure are accepted as positive processes of learning and the development of meanings and interpretations is inseparable from material processes and production. (Danvers, 2003, p. 52)

Brown (2006) argues for the application of new pedagogies, whereby the curriculum is redesigned around new pedagogical perspectives:

This is Dewey for the Digital Age: a profoundly social construction of understanding enabled by the Internet. The demand-pull approach draws students into a rich (sometimes virtual) learning community built around a practice. It is passion-based learning, intrinsically motivated by either wanting to become a member of that community of practice or just wanting to learn about, make, or perform something. Formal or informal, learning happens in part through a kind of reflective practicum, but here the reflection comes from being embedded in a social milieu supported by both a physical and virtual presence and inhabited by both amateurs and professionals. (Brown, 2006, pp. 2324)

Heutagogy is one such pedagogical strategy - characterised by Hase and Kenyon $(2001,2007)$ as focusing upon building student capabilities to deal with new and unknown problems and environments rather than simply building student competence for a set series of tasks. This is not to say educators should replace all guidance from education and simply rely upon student discovery, but involves designing the curriculum to scaffold a change of focus from teacher-directed pedagogy towards student-determined heutagogy, described by Luckin et al., (2010) as the Pedagogy-Andragogy-Heutagogy (PAH) Continuum. Where pedagogy refers to teacher-directed pedagogical strategies, andragogy refers to student-centred strategies, and heutagogy refers to student-determined strategies. More recently Blaschke and Hase (2019) have explored the alignment between heutagogy and mobile social media as an empowering ecology for self-determined learning. Two recent reviews of the literature around heutagogy highlight the need for more examples of the implementation of heutagogy in the context of building student capabilities in non-linear learning environments (Agonács \& Matos, 2019; Moore, 2020).

\section{Rhizomatic Learning and an Ecology of Resources}

Designing creative learning environments refocuses the curriculum and the role of the lecturer towards designing and creating triggering events to support ontological pedagogies - this involves new assessment designs and flexible learning space designs. Cormier (2008) termed this type of decentralisation of pedagogy as rhizomatic learning. Luckin (2008) argues for the development of learner centric ecologies of resources when using technology to scaffold learning. Pachler, Bachmair and Cook (2010) argue that such a learner-centric ecology of resources can be built around the use of mobile devices. The authors have built upon these ideas to design ecologies of resources to 
support creative learning environments in a variety of educational contexts (Cochrane et al., 2017). We argue that the design of an appropriate ecology of resources to support new pedagogical strategies is crucial to develop students' creative capabilities (Cochrane, 2014; Cochrane \& Antonczak, 2015).

\section{Design Based Research for Curriculum Redesign}

Design based research (DBR) provides a structured, four-phase iterative framework (McKenney \& Reeves, 2019) for designing authentic learning environments for education that go beyond simply transferring practice from one technology to another (Reeves \& Lin, 2020). We chose DBR as the foundation upon which to redesign the curriculum.

\section{Design-based research}

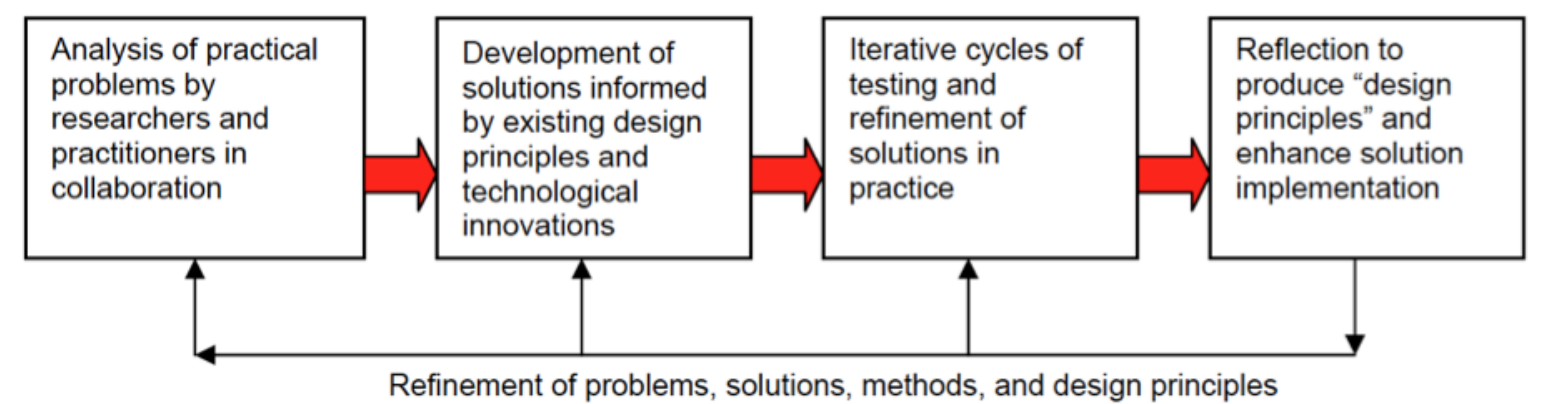

Figure 1: The four stages of Design Based Research, based upon McKenney and Reeves (2019).

The four phases of a curriculum design project are:

Phase 1: Analysis and exploration - Identification of the curriculum design problem - how to design an authentic student-centred project that is authentically scaffolded across a curriculum and the critical issues surrounding the specific learning environments. Followed by the exploration of supporting literature to identify initial design principles to address these issues.

Phase 2: Design and construction - Prototyping of the collaborative curriculum design informed by the identified design principles.

Phase 3: Evaluation and reflection - Evaluation of the prototype curriculum and subsequent collaborative curriculum redesign through user feedback (students and project team peers), and refinement of the design principles.

(Phase 2-3 Loop: Iterative redesign and re-evaluation of the collaborative curriculum design).

Phase 4: Theory building - Development of transferable design principles and dissemination of findings for application to other higher education learning contexts.

Within the curriculum design phase, curriculum design frameworks are utilized to inform the application of appropriate learning theory to learning activities and assessments - for example the ABC model (Young \& Perović, 2016), based upon Laurillard's conversational framework (Laurillard, 2001). While DBR has been promoted as an authentic and ethically-based approach to curriculum design, there are few examples of how to go about implementing a DBR framework in practice - this paper attempts to partially fill this gap in the literature.

\section{Methodology}

This section outlines the context of an example of a DBR framework applied to a specific curriculum area.

\section{Participants}


The Communication Design major, one of six majors in the Bachelor of Design (B.Des) including: Communication Design, Spatial Design, Industrial Design, Fashion Design, Digital Design and Textile Design. The Bachelor of Design is both the largest (A cohort of approximately 400 students in total per year across City and South campuses) and the most sought after area of study in the School of Art and Design at Auckland University of Technology, New Zealand, and one of the most successful programmes of its type in New Zealand, receiving over 450 first year applicants annually. The Communication Design major has been offered at the city campus for many years, has been delivered at the AUT South campus in Manukau, Auckland from 2014 onwards. The goal of this curriculum redesign project is to design a version of this major specifically for the new south campus of the university that is situated in a distinct cultural environment and the site of recently finished flexible learning spaces.

\section{Graduate Profile}

Bachelor of Design, graphic design graduates will have strong theoretical knowledge of graphic design, creativity, technological and design process capabilities, as well as the values that will prepare them for careers within a variety of different graphic design settings and contexts. They will be able to work effectively in collaborative teams to make positive social and economic impact through contemporary graphic design practices.

The following is the graduate profile for all students of the Bachelor of Design. Specialist graphic design capabilities are listed after the generic capabilities. A graduate of the Bachelor of Design will be able to:

a. Demonstrate broad conceptual knowledge of human-centred design, with in-depth-knowledge in one or more design specialisations. (Knowledge/Understanding)

b. Demonstrate an understanding of the broader contexts within which design operates. (Knowledge/Understanding)

c. Define project parameters, establish frameworks, and implement and manage projects and resources. (Inquiry/Research/Creativity)

d. Apply a range of contextual, theoretical and practice-led research practices and methodologies. (Inquiry/Research/Creativity)

e. Evaluate information, critically interrogate, analyse and frame problems, and present insights to identify opportunities for creativity and innovation. (Inquiry/Research/Creativity)

f. Integrate theory and practice through applied design work. (Skills/Application)

g. Apply creative thinking to iteratively develop and refine ideas and concepts. (Inquiry/Research/Creativity)

$\mathrm{h}$. Utilise a range of appropriate traditional and contemporary design media, materials, technologies and technical processes. (Skills/Application)

i. Collaborate with a range of people, within and across design and other disciplines. (Skills/Application)

j. Communicate effectively using oral, written and visual forms across a range of professional contexts. (Communication)

k. Demonstrate ethical responsibility, including a commitment to biculturalism and the principles of the Treaty of Waitangi, and design for improving social, cultural, and environmental wellbeing. (Ethical/Professional Dispositions)

As well as displaying the overall capabilities of the Bachelor of Design, a graduate of the graphic design major will be able to: apply specialist, design for social impact practices (Inquiry/Research/Creativity).

\section{Research Question}

The research question that frames our curriculum design project is:

How can we apply a design-based research curriculum design framework to scaffold the Pedagogy-AndragogyHeutagogy continuum within a graphic design degree?

\section{Initial Design Principles}

To guide the implementation of these changes in the curriculum we adopted a Design-Based Research methodology (McKenney \& Reeves, 2019). The design principles that guided the development of the curriculum redesign framework were drawn from our experiences of prior projects and the literature (Sinfield \& Cochrane, 2018, 2020; 
Steagall et al., 2016).

- Use a DBR methodology

- Create a collaborative curriculum design team

- Identify the foundational learning theories that match the graduate outcomes

- Design learning activities and assessments that scaffold the PAH continuum

- Develop a learner-centric ecology of resources

- Build iterative evaluation and redesign into the on-going curriculum design process

\section{Redesigning the Curriculum and Learning Spaces - A Prototype Proposal}

The curriculum redesign team was established as a collaboration between educational technology researchers and graphic design academic practitioners beginning in 2016 (Sinfield \& Cochrane, 2020; Steagall et al., 2016). The proposed curriculum redesign is based upon these prior experiences of introducing elements of learner-generated content and learner-generated contexts into the existing curriculum and is mapped against the Pedagogy-AndragogyHeutagogy continuum.

\section{Pedagogical Strategies}

Learning in the Bachelor of Design is focused on studio courses, which are supported by the integration of technology/media and contextual/theoretical courses as per figure 1 below, expanded in the following paragraphs.

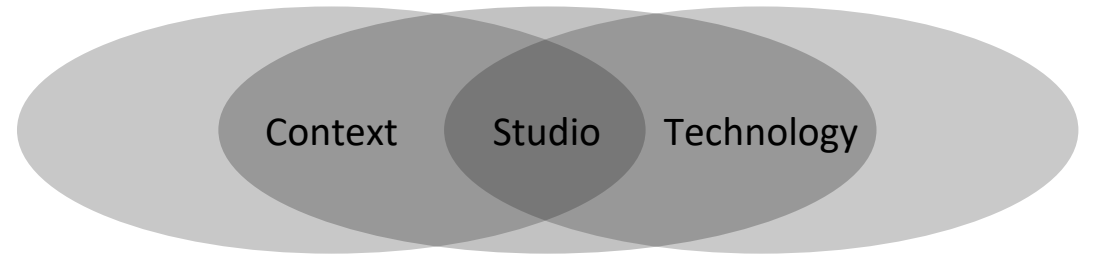

Figure 1. Relationship between 3 different types of Design courses

Studio-based design classrooms: the traditional Design Studio is based on an Atelier learning environment. The Atelier learning environment is especially suited to the Graphic Design model as it deals with the creative processing of ideas that needs to be shared in a collaborative manner. This has proven to have been a successful model over the years, in the traditional form of design education, but has more recently seen a shift in thinking as we move into a more digital model of learning and indeed away from the classical classroom structure. Design studio courses generally focus on design principles, processes, and methodologies and are underpinned by experiential learning through applied (hands-on) 'authentic' design problems and project work. Studio learning generally encompasses 'face to face' learning in studio spaces, augmented with digital technologies such as online learning and content management systems (For example Blackboard https://www.blackboard.com), digital tools and some use of social media and also focusing on collaborative projects.

Media/Technology: Design Media/Technology courses introduce and explore design media (digital software, technologies, materials, and associated technical processes) that are central to the design discipline area. These courses are generally also underpinned by experiential learning approaches in workshops/laboratory spaces, augmented with lectures/seminars. Learning is further augmented with digital technologies such as an online learning management system (Blackboard), digital tools and some use of social media.

Research/Context: These courses introduce and explore contextual, theoretical and critical issues that are central to the design discipline area. Scholarly research methods and approaches are introduced and explored. Learning is underpinned by lecture/seminar, as well as tutorial learning approaches. Learning is augmented with digital technologies such as online content systems (Blackboard), digital tools and some use of social media.

\section{Designing the Virtual Studio Environment}

With the development and opening of new flexible student and teaching spaces the university now has sufficient resources and is well-placed to introduce and offer this new major at the south campus. The university is well 
equipped with a range of teaching spaces, workshops and computer laboratories, and which will be available to the graphic design students at the South Auckland campus (Communication Design is already being taught at South campus). Of note, are the recent campus developments, which include a new, award-winning central student building at South Campus that provides a central hub and world-class facilities. The AUT library is appropriately resourced for this programme, including comprehensive electronic databases and student resources for exploration. Within these spaces there are many flexible spaces that can be utilised as student team-work spaces and collaborative environments distributed across the campuses but connected via wireless networking and cloud-based sharing platforms beyond utilising a traditional dedicated studio classroom.

A number of academically and professionally qualified staff with appropriate expertise exists within the School of Art and Design. Additional academic staff will also be appointed as the programme develops and grows, creating the opportunity to recruit lecturers with buy-in to the new pedagogical strategies embedded within the curriculum redesign. Visiting academics and industry partners will be involved as appropriate. The key design elements thus are the redesign of the structure and underlying pedagogies of the new curriculum, enabled by new technologies.

\section{An Ecology of Resources}

The project is supported through the establishment of a community of practice consisting of the course lecturers and educational researchers who share a common interest in collaboratively redesigning the curriculum around heutagogy or a student-determined learning environment. Within the context of graphic design, students need to learn the skills to collaborate in small teams, problem solve an array of new technologies, and blend artistic and digital literacies as creative enablers (Sinfield \& Cochrane, 2020). The curriculum must therefore move beyond a focus upon students demonstrating competency within defined environments to developing transferable capabilities or capacities to navigate the rapidly evolving creative interdisciplinary industries into which they will graduate. Graphic design is now part of a global community of designers, producers, and companies utilising technology to network, collaborate, co-create, share and publish within an environment that has moved from centralised control and distribution by select companies to on demand social media distribution channels. A key enabling technology within this context are user-owned mobile devices (for example the smartphone and mobile tablet) - connected multi-touch devices that can become the centre of an ecology of social media resources for engaging with a distributed learner cohort across the campus flexible spaces and a potentially global social media community (Figure 2). Mobile devices provide a link between a low-cost App-based interface to social media and professional graphic design production tools, where the typical cost of software ownership is several orders of magnitude lower than that for laptop or desktop versions of the software, and a more authentic physical interface via multi-touch than a computer keyboard and mouse. Blaschke and Hase (2019) argue for the symbiotic relationship between heutagogy and digital social media learning ecologies.

"The key principles of heutagogy - learner agency, self-efficacy and capability, reflection and metacognition, and non-linear learning - provide a foundation for designing and developing learning ecologies, the potential of which can be further maximized through the use of digital media." (Blaschke \& Hase, 2019, p. 1)

The Ecology of Resources (EoR) is defined by the core graduate attributes and learning outcomes, and real-world technologies that support these. These main elements may include, for example (Figure 2):

(1) a community-driven hub and discussion forum (connectivism)

(2) communication channels (social constructivism)

(3) opportunities for sharing practice (rhizomatic learning)

(4) collaboration across the wider network (brokering communities of practice)

(5) a repository for student work, such as an ePortfolio (learner-generated content)

(6) building a Bring Your Own Device (BYOD) infrastructure strategy (enabling learner-generated contexts)

In figure 2 we illustrate the core elements of a potential ecology of resources that maps key curriculum elements with heutagogy and the affordances of mobile social media platforms. 


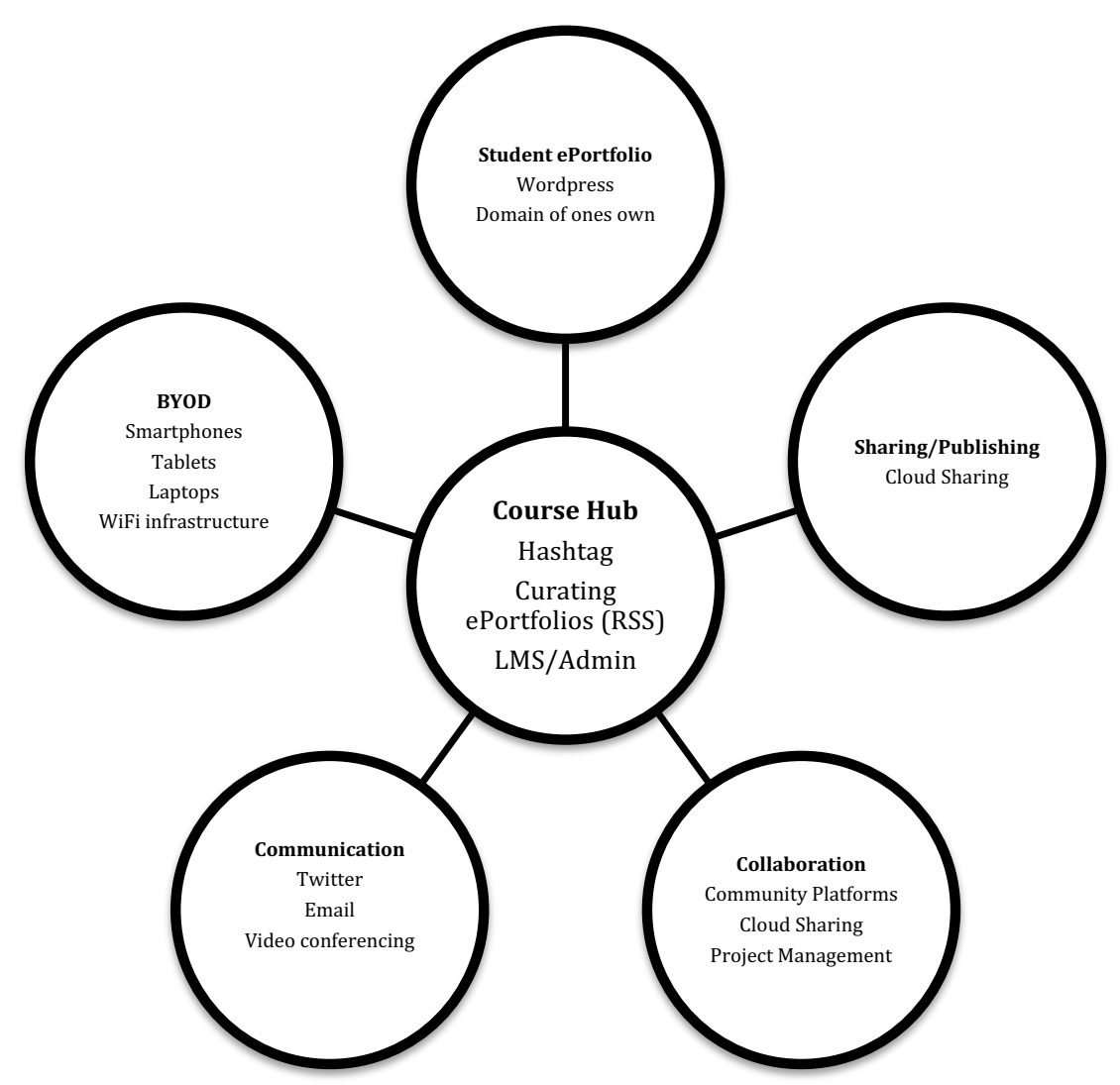

Figure 2: A social media ecology of resources to support the virtual studio

In the context of graphic design there are several mobile applications that are directly applicable to this ecology of resources, for example: Adobe Creative Cloud Apps, and a Behance ePortfolio. Most of these mobile applications are also directly applicable to other design-studio based contexts as well.

As the first stage of the DBR project this paper explores our choice of theoretical foundations and scoping of the initial prototype redesign of the course ecology.

\section{Curriculum Redesign - scaffolding the PAH continuum}

The proposed application of a DBR framework for a redesigned curriculum is mapped across the three years of the degree as outlined in this section of the paper.

The first year focuses on introducing and exploring fundamental graphic design concepts and principles including graphic composition, typography, static and dynamic image manipulation and creative design processes. This year scaffolds students from a teacher-directed pedagogy towards student-centred andragogy. A key goal is to assist students to develop experimental and critical thinking mindsets. The first year also includes an introduction to broader contextual issues (such as the relationship of culture and society to design), New Zealand bicultural contexts and Māori indigenous world views, along with an introduction to the role of the designer in community partnership and engagement. Fundamental static and moving image design technologies and processes are also introduced and explored.

The second year focuses on extending learning in year one more towards a student-determined (heutagogy) perspective and integrating time-based, dynamic and interactive graphic design approaches and technologies, as well as exploring more focused user-centred and design thinking approaches for graphic design. Key threshold concepts and practices such as design for social impact will also be introduced and integrated into studio project work. In the second semester, students are encouraged to identify and discuss personal aspirations, and are given opportunities to 
personalise design studio projects and engaging in collaborative community-based projects. An example of a semester two project that has been undertaken with current students is illustrated below:

Students utilise the theory of concrete poetry. Each student will research into and choose a published poem or write their own poem that reflects their chosen place within the area of Manukau. The brief is a typographical design brief. As such will convey the poem in a typographical form in a sympathetic manner to their chosen area. Suvantola (2002) notes that no "humanistic (or any other) definitions can provide a conclusive definition of place" (p. 29). The purpose of this is to broadcast to the wider community of Manukau, South Auckland and to use their chosen area for presenting the work. By presenting the work in this way was seen as a Koha [or gift] for the community of Manukau, South Auckland (Extracted from the student project brief proposal. 2017).

Concrete poetry or 'Size' poetry is poetry in which the typographical arrangement of words is as important in conveying the intended effect as the conventional elements of the poem, such as the meaning of words, rhythm, rhyme and so on. It is sometimes referred to as visual poetry, a term that has evolved to have distinct meaning of its own, but which shares the distinction of being poetry in which the visual elements are as important as the text. Key technologies introduced in the second semester include software for 2D and 3D learning, from moving text and images into mobile Virtual Reality (VR) and Augmented Reality (AR) for graphic design and communication. As noted, studio projects may be undertaken in partnership with local business and community groups.

The third year focuses on the application of graphic design more broadly within and across a range of situations, social contexts, a broad range of audiences/users and selected digital and moving image technologies. Students are involved in negotiating their learning as the pedagogical strategies embed heutagogy or student-determined learning environments. Students identify and explore personal interests within the graphic design area and develop individual approaches and methodologies. Students also undertake a professional and community placement in semester one. In semester two more advanced research approaches and theories and contexts within graphic design are explored, culminating in an in-depth semester long negotiated studio design project. This helps students prepare for industry or postgraduate study.

Thus, the design of the curriculum scaffolds a movement from teacher directed to student determined pedagogical strategies across the three years of the degree. Students also undertake one minor of their selection from a selection of 10 options in the School of Art and Design, and from a range of other minors located outside of the School. Table 1 outlines examples of courses in relationship to scaffolding the pedagogy-andragogy-heutagogy (PAH) continuum, facilitating a move from more teacher-directed learning activities in first year (5XX courses), student-centred learning activities in the second year (6XX courses), through to highly self-directed student learning in the third year (7XX courses).

Table 1: Prescriptions for courses

\begin{tabular}{|l|l|l|}
\hline Course & Description & $\begin{array}{l}\text { Scaffolding the PAH } \\
\text { Continuum }- \\
\text { pedagogical focus }\end{array}$ \\
\hline $\begin{array}{l}\text { GRAD511 } \\
\text { Stuphic Design I }\end{array}$ & $\begin{array}{l}\text { Fundamental graphic design concepts, principles and } \\
\text { processes are introduced and explored through practical and } \\
\text { applied design exercises. The emphasis is on creative } \\
\text { experimentation with typography, visual imagery and other } \\
\text { graphic elements to effectively visually communicate ideas } \\
\text { and concepts. Indigenous perspectives on creativity, design } \\
\text { processes, and idea ownership are also explored. }\end{array}$ & Pedagogy to Andragogy \\
\hline $\begin{array}{l}\text { GRAD513 } \\
\text { Graphic Design } \\
\text { Technology I }\end{array}$ & $\begin{array}{l}\text { Fundamental graphic design technologies and media are } \\
\text { introduced, explored, and experimented with. Technologies } \\
\text { include a range of digital design software and hardware, as } \\
\text { well as image construction and manipulation technologies that } \\
\text { are utilised in creative design processes. }\end{array}$ & Pedagogy to Andragogy \\
\hline
\end{tabular}




\begin{tabular}{|c|c|c|}
\hline $\begin{array}{l}\text { GRAD515 } \\
\text { Graphic Design } \\
\text { Contexts I }\end{array}$ & $\begin{array}{l}\text { Fundamental design contexts are introduced and explored. } \\
\text { These include the history of graphic design, contemporary } \\
\text { social, cultural and technological contexts as well as } \\
\text { indigenous Māori perspectives. This course will also } \\
\text { introduce the principles of critical thinking, and academic } \\
\text { writing. }\end{array}$ & Pedagogy to Andragogy \\
\hline $\begin{array}{l}\text { GRA512 } \\
\text { Graphic Design } \\
\text { Studio II }\end{array}$ & $\begin{array}{l}\text { Graphic design principles and processes are explored through } \\
\text { applied exercises and project work, leading to a range of } \\
\text { design outcomes. This will also include investigating and } \\
\text { exploring a range of design problems through typography, } \\
\text { visual imagery, moving image and time-based media, and } \\
\text { other dynamic elements. Students establish their individual } \\
\text { ePortfolios that will be taken through to the end of year3 and } \\
\text { on into their professional careers. }\end{array}$ & Andragogy \\
\hline $\begin{array}{l}\text { GRAD514 } \\
\text { Graphic Design } \\
\text { Technology II }\end{array}$ & $\begin{array}{l}\text { Time-based, dynamic design technologies and associated } \\
\text { materials and processes are explored and utilised. } \\
\text { Technologies include time-based, interactive design software } \\
\text { for the creation of motion graphics and moving image and } \\
\text { interactive graphic publications, as well as more advanced } \\
\text { design and image manipulation technologies. }\end{array}$ & Pedagogy to Andragogy \\
\hline $\begin{array}{l}\text { GRAD611 } \\
\text { Graphic Design } \\
\text { Studio III }\end{array}$ & $\begin{array}{l}\text { Design practices and capabilities are further developed } \\
\text { through engagement with a series of problem-based applied } \\
\text { graphic design projects. Audience perspectives, user-centred } \\
\text { design and design thinking practices are introduced and } \\
\text { explored. }\end{array}$ & Andragogy \\
\hline $\begin{array}{l}\text { GRAD613 } \\
\text { Design for Social } \\
\text { Impact }\end{array}$ & $\begin{array}{l}\text { Key social concepts including political, interpersonal and } \\
\text { cultural systems, Māori indigenous perspectives, along with } \\
\text { contemporary social issues are introduced and critically } \\
\text { discussed. These are then explored in relation to fundamental } \\
\text { Design for Social Impact approaches and practices that when } \\
\text { enacted create the potential for positive social change. }\end{array}$ & Pedagogy to andragogy \\
\hline $\begin{array}{l}\text { GRAD614 } \\
\text { Graphic Design } \\
\text { Technology III }\end{array}$ & $\begin{array}{l}\text { Advanced graphic design technologies, software and } \\
\text { associated processes are explored, experimented with, and } \\
\text { utilised. Technologies include, but not limited to, interactive } \\
\text { mobile technologies, Virtual Reality (VR) and Augmented } \\
\text { Reality (AR), along with other new and emerging } \\
\text { technologies. Emergent and future scenarios for graphic } \\
\text { design technologies are also critically discussed and explored. }\end{array}$ & Andragogy to Heutagogy \\
\hline $\begin{array}{l}\text { GRAD612 } \\
\text { Graphic Design } \\
\text { Studio IV }\end{array}$ & $\begin{array}{l}\text { Individual graphic design practices are developed through the } \\
\text { engagement with applied design projects, which may be } \\
\text { undertaken in partnership with community-based groups and } \\
\text { the graphic design industry. Concepts from technology and } \\
\text { contextual courses are further integrated into learning. }\end{array}$ & Andragogy to Heutagogy \\
\hline $\begin{array}{l}\text { GRAD711 } \\
\text { Graphic Design } \\
\text { Studio V }\end{array}$ & $\begin{array}{l}\text { Design practices are further extended through the undertaking } \\
\text { of personally orientated design projects underpinned by } \\
\text { 'authentic', socially orientated issues and design problems. } \\
\text { Students are encouraged to consider and explore their } \\
\text { personal interests in graphic design. }\end{array}$ & Andragogy to Heutagogy \\
\hline $\begin{array}{l}\text { GRAD714 } \\
\text { Industry/Comm } \\
\text { unity Placement }\end{array}$ & $\begin{array}{l}\text { An industry or community placement is negotiated by the } \\
\text { student and is undertaken with an industry or community } \\
\text { group to develop professional mindsets and capabilities. A } \\
\text { document that captures reflections and learning from the } \\
\text { placement is produced along with a digital presentation. }\end{array}$ & Heutagogy \\
\hline
\end{tabular}




\begin{tabular}{|l|l|l|}
\hline $\begin{array}{l}\text { GRAD712 } \\
\text { Graphic Design } \\
\text { Studio VI }\end{array}$ & $\begin{array}{l}\text { Advanced design capabilities are developed through } \\
\text { engagement with a negotiated, professionally aligned, } \\
\text { capstone design project. Design work will deepen personal } \\
\text { knowledge, extend creativity, encourage critical thinking } \\
\text { skills and establish industry-ready reflective design practice. }\end{array}$ & Heutagogy \\
\hline $\begin{array}{l}\text { GRAD713 } \\
\text { Graphic Design } \\
\text { Contexts II }\end{array}$ & $\begin{array}{l}\text { A research-based, scholarly document that accompanies } \\
\text { capstone design project work undertaken in the Studio VI } \\
\text { paper is researched, developed and written. The document } \\
\text { explores contextual, theoretical and methodological } \\
\text { perspectives in relation to the project. This course underpins } \\
\text { further study at postgraduate level. Student-owned ePortfolios } \\
\text { are used to curate their body of work throughout the degree } \\
\text { and form the basis of an on-going professional ePortfolio. }\end{array}$ & Heutagogy \\
\hline
\end{tabular}

\section{Assessment and Moderation Design}

Assessment within the Bachelor of Design, Graphic Design major will be consistent with the philosophy and aims of the programme and, as far as possible, reflect professional/industry practices and standards. Assessment will measure student achievement of learning outcomes and record the attainment of student knowledge and capabilities. Assessment is also an integral part of the learning process and will further develop independent learning skills.

A variety of formative and summative assessment approaches will be used to meet the different purposes of assessment. The applied and creative nature of the degree will be reflected in the assessment programme, which will include a mix of student-negotiated individual and group project work, reports, presentations, and research assignments. Student work will be curated through the development of individual ePortfolios that will showcase their creative thinking and projects. Peer feedback through ePortfolio commenting and lecturer formative feedback will be integrated into the activities and assessment processes. Curated student-owned ePortfolios will create a shared community of practice throughout the degree. Student projects will be showcased through physical and enhanced virtual environment exhibition events. All summative assessments will be subject to moderation.

Pre and post moderation will be carried out for every assessment event. The curriculum leader will determine the moderation team and will ensure the moderation process is effective. All moderation will be reported on in the 'Paper Summary Report for Exam Board'. Final design studio assessment events (Graphic Design Studio VI) will be subject to external moderation.

\section{Discussion}

This paper presents the initial stages of a curriculum redesign project informed by a design-based research methodology. As such the paper outlines the initial analysis and exploration stage and the prototype curriculum redesign stages. The next steps in the project will be the implementation and evaluation stages that will inform further redesign. The critical identified implications of the initial stages of the redesign project are that a redesign of the concept of the design studio requires an integrated curriculum redesign to map the introduction of flexible and authentic physical and virtual learning spaces with the graduate outcomes. While we have explored the literature surrounding new pedagogies sand creativity, as highlighted by Moore (2020), Agonacs and Matos (2019) we have found only little evidence of curriculum redesign models or examples that implement these theories and strategies, for example (Blaschke, 2016). Therefore, in this paper we present our work in progress as a pragmatic example of the application of scaffolding the PAH continuum within curriculum design.

\section{Design principles for re/designing studio-based learning}

Our initial design principles were refined through several iterations of prior curriculum design projects, and included:

- Use a DBR methodology

- Create a collaborative curriculum design team

- Identify the foundational learning theories that match the graduate outcomes

- Design learning activities and assessments that scaffold the PAH continuum 
- Develop a learner-centric ecology of resources

- Build iterative evaluation and redesign into the on-going curriculum design process

The implications of these design principles for other curriculum contexts are briefly discussed here. All of the six design principles are interdependent, building upon the foundation of a four-stage design-based research methodology, and cannot be seen as independent steps or stages. An integrative approach to how these design principles are applied to the curriculum design process

Identifying the foundational learning theories that match the graduate outcomes will also guide the design of the learning activities and assessments, and the choice or negotiation of a supporting ecology of resources to achieve these activities and assessment outcomes. For example, the six elements of our chosen EoR were mapped directly to supporting learning theories and frameworks, as illustrated in Figure 2:

(1) a community-driven hub and discussion forum (connectivism)

(2) communication channels (social constructivism)

(3) opportunities for sharing practice (rhizomatic learning)

(4) collaboration across the wider network (brokering communities of practice)

(5) a repository for student work, such as an ePortfolio (learner-generated content)

(6) building a BYOD infrastructure strategy (enabling learner-generated contexts)

Using DBR the curriculum design process is implemented across four iterative stages, and rather than being a linear approach that must be fully completed before the 'delivery' of the course, allows for rapid prototyping and iterative evaluation and redesign of elements of the course design, including activities and assessments across the length of the course.

\section{Ethical considerations}

Establishing an ethical research foundation for this project was achieved through applying to AUTEC (Auckland University of Technology Ethics Committee). This was to protect all involved in the project and to establish a working framework for the project that included information sheets and consent forms for participation in feedback and evaluation of the curriculum redesign activities and assessments. Ethics approval was granted on $11^{\text {th }}$ May 2018, number $17 / 4$.

Issues that should be explicitly discussed with both students and educators include the professional use of social media, the intellectual and copyright implications of using cloud-based publishing and sharing platforms as part of the negotiated ecology of resources, and how establishing institutional managed versions of ePortfolios and cloud sharing platforms can mitigate some of these issues. Infrastructure support is also required through appropriate access to connectivity (Campus-based WiFi and presentation systems for example) and ensuring equity of student ownership of digital devices. One way to manage these issues is to explicitly include a representative of the institutional IT support team within the collaborative curriculum design team (Salmon \& Angood, 2013).

\section{Applying the framework to summer student scholarships and research project}

While the proposed curriculum redesign is still a theoretical model at this point - it provides an example of the first two stages of a DBR framework for curriculum redesign. However, the implementation of heutagogy within the design curriculum is constrained by the current accreditation and assessment requirements of the university and is thus an iterative redesign of existing curricula strategies rather than a radical reinterpretation of studio-based design classrooms. To explore the framework beyond these boundaries the curriculum design team applied the framework to the design of an authentic student team activity based upon an elective summer student scholarship project in graphic design (Cochrane \& Sinfield, 2019; Sinfield \& Cochrane, 2019). The project involved a collaborative transdisciplinary team of educational researchers, practitioners, student designers, and the Auckland Hospital Design Lab in the design of innovative technology enhanced solutions that positively enhance health care practitioner and patient experiences. Using Design Based Research, the project explored real world problems in health care to design and evaluate prototype solutions. The project illustrates the application of design principles for innovative learning environments that facilitate student-determined learning in real world scenarios.

What was the project purpose?

The project explored the potential for enhancing healthcare through wearable and mobile technologies, such as 
tracking patient biometrics and location, optimising and digitising patient data, and providing accessible feedback to health practitioners. Hospitals are ill-equipped to deal with designing innovative solutions to health education problems. Hospitals are large organisations carrying decades of established practices and practitioners and clinicians who are reticent to change practices in technology use rapidly in response to refocusing upon pre-hospital and outpatient care (for example). However, universities have expertise in supervising and mentoring student research teams to solve real-world problems. By building authentic collaboration between university research teams and hospital design teams innovative solutions to practical health care problems can be solved. The project also provides students with an authentic learning experience (Bosco \& Fern, 2014). The summer student work experience project is part of a longer term collaboration between university students, academic supervisors, and district health providers to collaborate on real world projects that benefit the wider community through developing solutions to health care problems in collaboration with a local district health board (ADHB or Auckland District Health Board). In this project communication design students applied to form design teams, selected and supervised by university academics, to address design briefs from the district health board's Design Lab (Ara Manawa).

The design brief: development of a nursing shift planner

It is common practice for nurses to plan their shift using a shift planner. It acts as a reminder for what tasks need to be completed for different patients and when. It is an A4 piece of paper that normally has a 5x10 table where the nurse can write patient's details, plan of care and the needs of the patients for each hour of their shift. The nurse handwrites these details before the shift and handover commences, and then crosses them off once they have been completed. Ward nurses care up to 6-7 patients in a shift.

\section{Problem Statement}

The process of writing the details (diagnosis, past medical history and plan) for each patient can be time consuming, especially if there hasn't been an acute change in condition. This information is already entered on another electronic database called 'Trendcare', however this is only used for handover sheets.

\section{Project Goal}

The aim is to develop an electronic shift planner that can be used on a mobile device that included reminders/notifications when a task is due. Once a task has been completed, the nurse can swipe the task away or mark as complete. If a nurse is running behind on their tasks, an alert can be sent to the Charge Nurse or coordinator to inform them that their teams are behind schedule, so they are able to organise extra help where necessary.

\section{Results}

The student design team met regularly with all the project stakeholders and the research supervision team. Microsoft Teams was used to share project progress and files across the collaborative project team, a Twitter Hashtag (\#Studio602) was used to share and curate project milestones (https://twitter.com/i/events/1229216737704329216?s=20), and a student team blog site was used to curate and share project resources and prototypes for feedback (https://studio602.home.blog). After a rapid prototyping and stakeholder feedback loop, the student design team presented a design solution wireframe and scoping documentation at the end of the ten-week project timeframe. The feedback from the students involved in the summer scholarship project and the ADHB staff was extremely positive (https://www.aramanawa.com/blog/2020/5/8/studio602-activity-and-planning-tools), leading to a longer-term collaboration with the ADHB as a professional partner in providing authentic learning projects for our students. "Auckland DHB has lots of opportunities for our tertiary partners and their students to help us think differently about how we work. Thanks to AUT, Auckland DHB nurses, and the Auckland Digital team for your support!" (Ara Manawa blog post, 2020).

\section{Limitations and future directions}

The implementation of the curriculum redesign project is based within the boundaries of a specific pre-existing curriculum context, but we believe the design principles and framework that it illustrates are transferable to a range of learning environments and contexts. This will be explored in future research in collaboration with other curriculum context practitioners. 


\section{Conclusions}

The paper discusses an example of reconceptualising design studio-based higher education to incorporate flexible and authentic learning activities, assessments and learning spaces while mapping these to the pedagogy-andragogyheutagogy continuum. The theoretical curriculum design framework serves as an example of a DBR methodology for curriculum redesign to focus upon building student creativity, integrating new technologies, and new pedagogical strategies, informed by explicit links to learning theories and frameworks that define an appropriate ecology of resources to implement the proposed authentic learning activities and assessments. The framework is illustrated within the bounds of a redesign of a traditional studio-based design curriculum, and more radically illustrated in the design of an elective summer school student design project.

\section{References}

Agonács, N., \& Matos, J. F. (2019). Heutagogy and self-determined learning: a review of the published literature on the application and implementation of the theory. Open Learning: The Journal of Open, Distance and eLearning, 34(3), 223-240. https://doi.org/10.1080/02680513.2018.1562329

Blaschke, L. M. (2016). Strategies for Implementing Self-Determined Learning (Heutagogy) within Education: A Comparison of Three Institutions (Australia, South Africa, and Israel) [Master's, Carl von Ossietzky Universität Oldenburg]. https://www.researchgate.net/publication/312916350 Strategies for Implementing SelfDetermined Learning Heutagogy within Education A Comparison of Three Institutions Australia So uth Africa and Israel

Blaschke, L. M., \& Hase, S. (2019). Heutagogy and digital media networks: Setting students on the path to lifelong learning. Pacific Journal of Technology Enhanced Learning, 1(1), 1-14. https://doi.org/https://doi.org/10.24135/pjtel.v1i1.1

Bosco, A. M., \& Fern, S. (2014). Embedding of authentic assessment in work-integrated learning curriculum. AsiaPacific Journal of Cooperative Education, 15(4), 281-290. https://www.ijwil.org/files/APJCE 15 4 281_290.pdf

Brown, J. S. (2006, September/October). New Learning Environments for the 21st Century: Exploring the Edge. Change: The magazine of higher learning, 38(5), 18-24. https://doi.org/10.3200/CHNG.38.5.18-24

Cochrane, T. (2014). Critical success factors for transforming pedagogy with mobile Web 2.0. British Journal of Educational Technology, 45(1), 65-82. https://doi.org/10.1111/j.1467-8535.2012.01384.x

Cochrane, T., \& Antonczak, L. (2015). Designing Creative Learning Environments. Interaction Design and Architecture(s) Journal - IxD\&A, N.24, 125-144. http://www.mifav.uniroma2.it/inevent/events/idea2010/index.php?s=10\&a=11\&link=ToC_24_P\&link=24 $\underline{8 \text { abstract }}$

Cochrane, T., Cook, S., Aiello, S., Christie, D., Sinfield, D., Steagall, M., \& Aguayo, C. (2017). A DBR Framework for Designing Mobile Virtual Reality Learning Environments. Australasian Journal of Educational Technology (AJET), 33(6), 54-68. https://doi.org/https://doi.org/10.14742/ajet.3613

Cochrane, T., \& Sinfield, D. (2019, 19 February). A Model for Designing Authentic Learning: Summer Student Scholarships. Pacific Journal of Technology Enhanced Learning, 2(1), 8. https://doi.org/https://doi.org/10.24135/pjtel.v2i1.29

Cormier, D. (2008). Rhizomatic education: Community as curriculum. Innovate, 4(5), np. http://davecormier.com/edblog/2008/06/03/rhizomatic-education-community-as-curriculum/

Danvers, J. (2003). Towards a radical pedagogy: Provisional notes on learning and teaching in art \& design. International Journal of Art \& Design Education, 22(1), 47-57. https://doi.org/10.1111/1468-5949.00338

DesignCo, \& PwC. (2017). The Value of Design to New Zealand. DesignCo. https://creative.massey.ac.nz/media/789464/the-value-of-design design-co-report-exec-summary.pdf

Edwards, J. (2017). For every $£ 154$ newspapers lose in print revenue, they gain only $£ 5$ on the digital side. Business Insider Australia. Retrieved 14 December from https://www.businessinsider.com.au/statistics-smartphonesprint-newspaper-revenues-2017-2? $\mathrm{r}=\mathrm{UK} \& \mathrm{IR}=\mathrm{T}$

Hase, S., \& Kenyon, C. (2001). From Andragogy to Heutagogy. ultiBASE Articles(December), 1-10. http://www.psy.gla.ac.uk/ steve/pr/Heutagogy.html 
Hase, S., \& Kenyon, C. (2007). Heutagogy: a child of complexity theory. Complicity: an International Journal of Complexity and Education, 4(1), 111-118. https://doi.org/doi.org/10.29173/cmplct8766

Laurillard, D. (2001). Rethinking University Teaching: a framework for the effective use of educational technology (Second ed.). Routledge.

Luckin, R. (2008, February). The learner centric ecology of resources: A framework for using technology to scaffold learning. Computers \& Education, 50(2), 449-462. https://doi.org/10.1016/j.compedu.2007.09.018 (Development, Disruption \& Debate - Selected Contributions from the CAL 07 Conference)

Luckin, R., Clark, W., Garnett, F., Whitworth, A., Akass, J., Cook, J., Day, P., Ecclesfield, N., Hamilton, T., \& Robertson, J. (2010). Learner-Generated Contexts: A Framework to Support the Effective Use of Technology for Learning. In M. Lee \& C. McLoughlin (Eds.), Web 2.0-Based E-Learning: Applying Social Informatics for Tertiary Teaching (pp. 70-84). IGI Global. https://doi.org/10.4018/978-1-60566-2947.ch004

McKenney, S., \& Reeves, T. (2019). Conducting educational design research (2nd ed.). Routledge. https://doi.org/10.4324/9781315105642

Ministry of Education. (2017). Digital Technologies: Hangarau Matihiko [PDF]. https://education.govt.nz/assets/Documents/Ministry/consultations/DT-consultation/DTCP1701-DigitalTechnologies-Hangarau-Matihiko-ENG.pdf

Moore, R. L. (2020, 2020/07/02). Developing lifelong learning with heutagogy: contexts, critiques, and challenges. Distance Education, 41(3), 381-401. https://doi.org/10.1080/01587919.2020.1766949

Pachler, N., Bachmair, B., \& Cook, J. (2010). Mobile learning: Structures, agency, practices. Springer. http:/www.springerlink.com/content/978-1-4419-0584-0

http://books.google.co.nz/books?id=4wic3O1Sf0EC\&lpg=PA164\&ots=QYLzFvLQG5\&dq=02B $\% 22$ continuity $\% 20$ of $\% 20$ learning $\% 20$ activities $\% 20$ in $\% 20$ different $\% 20$ contexts $\% 22 \% 20 \% 2 \mathrm{BW}$ ali\&pg $=\mathrm{PR} 6 \# \mathrm{v}=$ onepage\&q= $+\% 22$ continuity $\% 20$ of $\% 20$ learning $\% 20$ activities $\% 20 \mathrm{in} \% 20$ different $\% 20$ contexts $\% 22 \% 20+$ Wali\&f $=$ false

Reeves, T. C., \& Lin, L. (2020, 2020/07/26). The research we have is not the research we need. Educational Technology Research and Development. https://doi.org/10.1007/s11423-020-09811-3

Salmon, G., \& Angood, R. (2013, November). Sleeping with the enemy. British Journal of Educational Technology, 44(6), 916-925. https://doi.org/10.1111/bjet.12097

Sinfield, D., \& Cochrane, T. (2018, 15th February). Designing the changing classroom. SoTEL: Scholarship of Technology Enhanced Learning 2018, Auckland University of Technology, Manukau, New Zealand.

Sinfield, D., \& Cochrane, T. (2019, 2-5 December). Developing a DBR Model for Designing Authentic Healthcare Solutions: Mobile and Wearable Technologies. ASCILITE 2019: 36th International Conference on Innovation, Practice and Research in the Use of Educational Technologies in Tertiary Education, Singapore University of Social Sciences (SUSS), Singapore.

Sinfield, D., \& Cochrane, T. (2020). Augmenting Visual Design: Designing the changing classroom. E-Learning and Digital Media, 17(5), 365-387. https://doi.org/10.1177/2042753018773769

Steagall, M., Sinfield, D., Cochrane, T., \& Tolutau, T. (2016, 14-16 November). Contextualising the classroom: Using Google Maps and 360 degree imagery to augment the undergraduate design environment. ICERI2016 Proceedings: the 9th annual International Conference of Education, Research and Innovation, Seville, Spain.

Watson, A. (2020, 10 November). Film Industry - statistics \& facts. Statistica. Retrieved 14 December from https://www.statista.com/topics/964/film/

Young, C., \& Perović, N. (2016). Rapid and Creative Course Design: As Easy as ABC? Procedia - Social and Behavioral Sciences, 228, 390-395. https://doi.org/10.1016/j.sbspro.2016.07.058 